\title{
Incidental detection of probable meningioma in brain scintigraphy using ${ }^{99 \mathrm{~m} T c-T R O D A T-1}$
}

Detecção acidental de provável meningioma na cintilografia cerebral utilizando 99mTc-TRODAT-1 Taise Vitor ${ }^{1}$, Guilherme Campos Carvalho Neto ${ }^{1}$, Solange Amorim Nogueira ${ }^{1}$, Jairo Wagner ${ }^{1}$, André C. Felício ${ }^{1}$

An 84-year-old woman underwent a dopamine transporter (DAT) study to investigate a non-levodopa-responsive parkinsonism. A SPECT brain scan was conducted four hours after intravenous administration of $1110 \mathrm{MBq}$ (megabecquerels) equivalent to $30 \mathrm{mCi}$ (millicuries) of ${ }^{99 \mathrm{~m} T c-T R O D A T-1 . ~ T h e ~}$ study revealed a significant uptake deficit of radiopharmaceuticals in the striatum. The semi-quantitative analysis of density of DAT showed radiopharmaceutical uptake indexes of 0.40 and 0.55 in the right and left side of the striatum, respectively. In addition, the right:left ratio was 0.73 . As well, scintigraphy images showed intense uptake of the radiopharmaceutical in the extra-axial left frontal lobe consistent with meningioma in a subsequent magnetic resonance imaging (MRI) study (Figure). The anatomical MRI sequences showed an intensely enhancing extra-axial mass in the left frontal lobe measuring about $2.8 \times 4.1 \times 4.1 \mathrm{~cm}$ with a broad dural base and heterogeneous
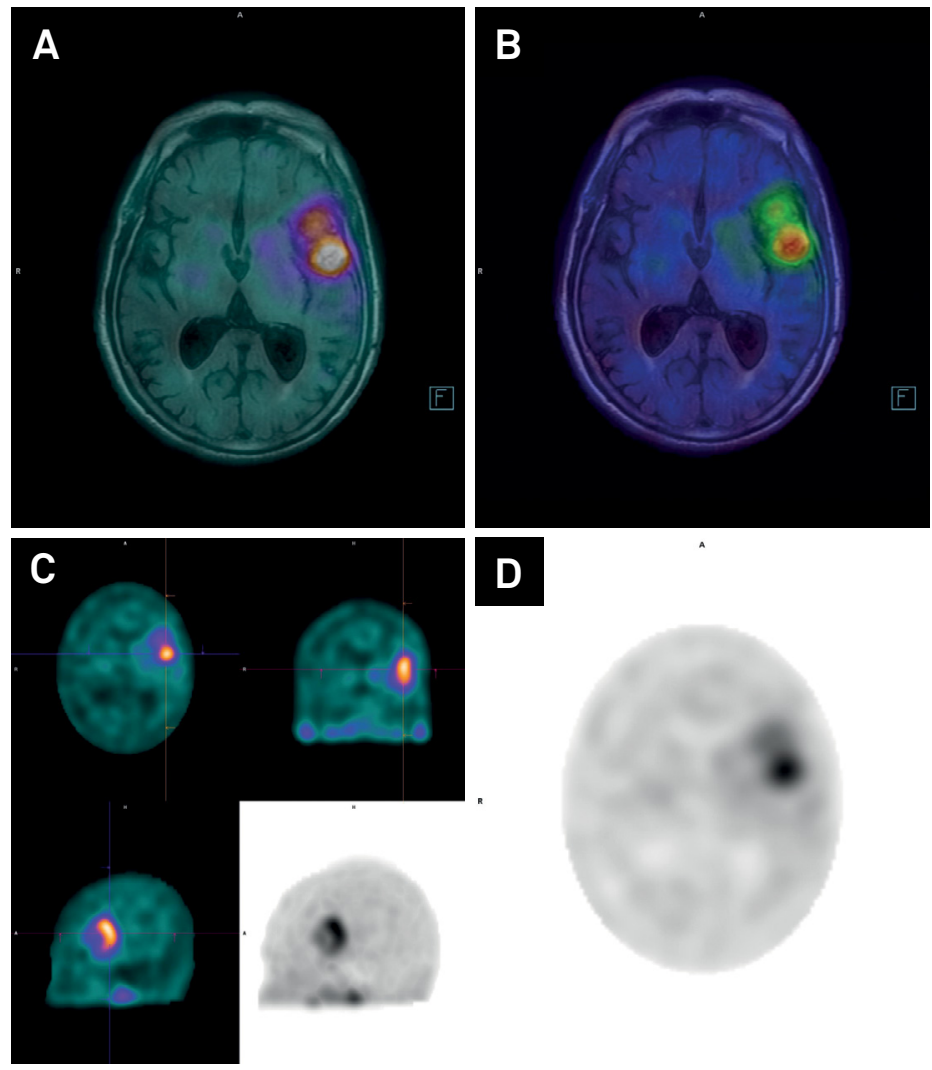

D

Figure. Dopamine transporter (DAT) imaging with SPECT/CT was performed four hours after IV injection of $1110 \mathrm{MBq}$ (30 mCi) of 99mTC-TRODAT-1. Fused SPECT/MRI axial slices ( $A$ and B) and SPECT (C and D). The study revealed significant reduction of radiotracer uptake in the striatum bilaterally. As well, a remarkable uptake of the radiopharmaceutical can be seen in the tumoral left frontal extra-axial mass. SPECT: single-photon emission computed tomography; MRI: magnetic resonance imaging; CT: computed tomography.

${ }^{1}$ Hospital Israelita Albert Einstein, Departamento de Medina Nuclear, São Paulo SP, Brasil.

Correspondence: Taise Vitor; Departamento de Medina Nuclear, Hospital Israelita Albert Einstein; Avenida Albert Einstein, 627; 05652-900 São Paulo SP, Brasil; E-mail: taise.vitor@einstein.br

Conflict of interest: There is no conflict of interest to declare.

Received 06 July 2016; Received in final form 16 September 2016; Accepted 31 October 2016. 
signal intensity on T2-weighted images and a large area of edema surrounding the lesion.

Brain tumors are a rare cause of parkinsonism ${ }^{1}$ and of them, meningiomas are the leading ones. In our patient, the tumor had neither signs of compression nor an expansive effect that could justify dopaminergic pathway compromise. In fact, the majority of brain tumors found in patients with parkinsonism are incidental ${ }^{2,3,4,5}$, and surgery was not recommended in our patient.

\section{References}

1. Takao Y, Agari T, Kambara H, Ichikawa T, Kurozumi K,

Ono S et al. Parkinsonism related to brain tumors: a case report and review of the literature. Open Neurosurg J. 2009;2(1):4-7. https://doi.org/10.2174/1876529700902010004

2. Biancheri-Mounicq I, Colombie M, Pin JC, Lecoanet A, Adam-Tariel F. Unexpected finding on I-123 FP-CIT SPECT leading to the diagnosis of cerebral meningioma. Clin Nucl Med. 2011;36(2):156-7. https://doi.org/10.1097/RLU.0b013e318203bebf

3. Chiu YL, Hu C, Li JY, Weng MJ, Lin WC, Peng NJ. An incidental finding of cerebral meningioma on $99 \mathrm{mTc}$-TRODAT-1 dopamine transporter SPECT/CT. Clin Nucl Med. 2012;37(9):899-900. https://doi.org/10.1097/RLU.0b013e31825b271f.

4. Boronat-Ferrater M, Lorenzo-Bosquet C, Leon A, Aguadé-Bruix S, Rossi-Seoane S, Hernández-Vara J et al. Unexpected I-123 FP-CIT uptake in a brain tumor. Clin Nucl Med. 2009;34(9):608-9. https://doi.org/10.1097/RLU.0b013e3181b06a59

5. Song IU, Lee SH, Chung YA. The incidental suggestive meningioma presenting as high 18F FP-CIT uptake on PET/CT study. Clin Nucl Med. 2014;39(1):e97-8. https://doi.org/10.1097/RLU.0b013e3182815d16 